\title{
BUILDING A CULTURE OF CREATIVE THINKING IN BUSINESS STUDIES
}

\author{
Nida Mačerauskienè \\ Vilniaus kolegija/ University of Applied Sciences, Lithuania
}

\begin{abstract}
Creativity is considered as an intangible characteristic that drives business to success. Creative persons play an important role in fostering both technical and social innovation and progress. Contemporary higher education graduates are expected to possess soft skills including creative thinking, problem-solving, critical thinking, flexibility, motivation, positivity and others. Therefore, the research was designed with the aim to enhance the understanding of the concepts of creativity and creative thinking and to address the question of how creativity and the process which we use when we come up with a new idea can be enhanced within and by higher education institutions. This study examines a creativity-driven study environment to promote a safe, non-judgmental atmosphere and the Creative Platform process meant to develop creativity during regular practical tasks to make it an involuntary reflex and to discover new viewpoints, perspectives, and solutions to any business problem. The framework of the research is based on the analysis of literature and experimental research methods. The results revealed that using special techniques, purposeful creative thinking can be developed beyond creativity subject. Moreover, interdisciplinarity teams lead to better solutions.
\end{abstract}

Keywords: business studies, creativity, Creativity Platform, creative thinking.

\section{Introduction}

It is a time of societal transformation, changes, and innovations. We used to study and practice hard to acquire hard skills - a prove of our competence. Nowadays ignoring soft skills - critical thinking, creativity, flexibility, communication, teamwork, adaptability, and others, is one of the principal career mistakes one could make. In the coming decades, not much progress will be made without creative thinking.

No doubt the focus should be laid on transforming the teaching and learning process at higher education institutions. The teaching-learning process should continually foster creative thinking and creativity should become an integral part of any studies. 
The article aims at investigating the concept and the main elements of creativity as well as their impact on the creative result. To achieve the aim the following tasks were set: to explore the elements of creativity; to introduce the Creative Platform paradigm to be used to enhance creativity in business studies; and to organize the idea generation sessions at the higher education institutions providing studies in the business field in three different countries - Austria, France, and Vietnam.

85 students participated in the 8-hour idea generation sessions under the Creative Platform methodology. The received data was analyzed and the results were discussed as well as further research possibilities indicated.

\section{Literature review}

With reference to the previous Mačerauskienè and TurčinskaitèBalčiūnienè article Do differences make a difference? The case based on the creativity platform (2017) as a part of the result of the longitudinal research, we should define the concepts of creativity and creative thinking. Creativity is commonly defined as the process of generating new ideas that are original, practical and valuable solutions to the existing problems (Barron, 1988; MacKinnon, 1962; Guilford, 1967; Sternberg \& Kaufman, 2010). Yet the process is a somewhat different one for each person. A pioneering model of four stages of the creative process conceptualizes the architecture of creativity (Wallas, 1926) (see fig. 1.).

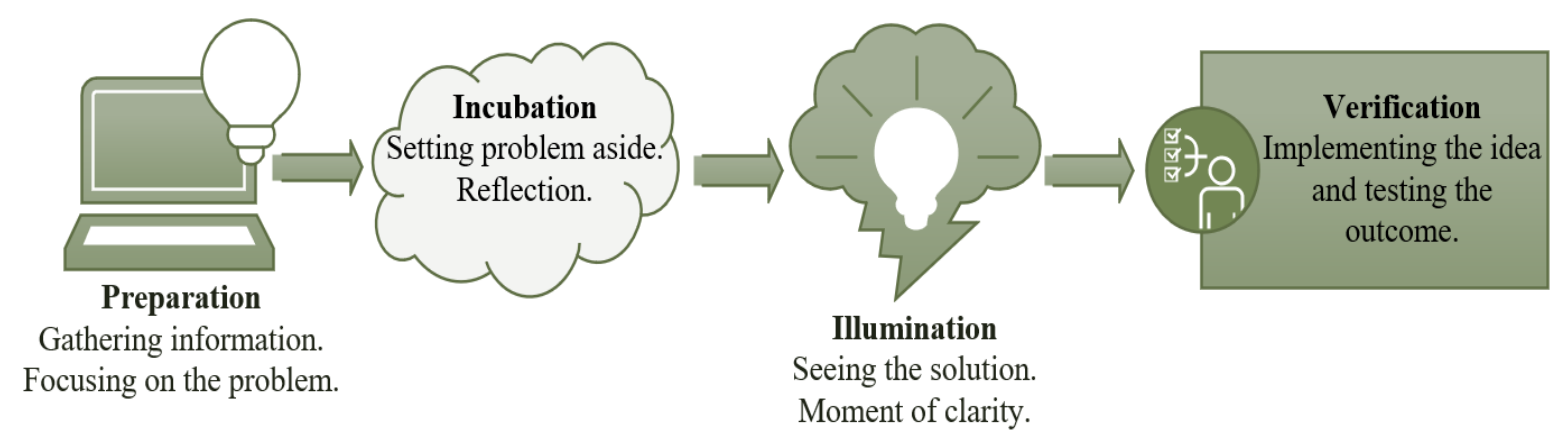

Figure 1 The process of generating new ideas (Adapted from The art of thought (p. 10) by G. Wallas, 1926, London: Jonathan Cape)

If we dig deeper into the definition of creativity, we discover other worth mentioning implications. Creativity implies 1. An aspect of the creative product - outcome or result of the creative process; 2 . An aspect of the creative 
agent/ person; 3. An aspect of the creative environment/ press (Rhodes, 1961; Brown, 1989; Davis, 2004).

Plucker, Beghetto and Dow (2004), Tardif and Sternberg (1988) recognize An aspect of the creative product as the most objective approach to creativity - a specific solution to a problem or evaluation of a concrete product. These are new mechanisms, programs, tools, publications, pieces of music, services, etc. Creativity studies emphasize that the outcome or result of the creative process must be innovative, exclusive, and valuable.

Besemer (1998) and Besemer and O'Quin (1999) identified three key factors of the creative product: originality (e.g., original, surprising), quality (e.g., logical, useful), and elegance (e.g., organic, well crafted).

The creative product often depends on the aspect of the creative person or personality. Creative achievement requires several personality attributes. Attention is given to flexibility, openness to new ideas, self-confidence, tolerance to ambiguity, courage, curiosity, and persistence (Dawson \& Andriopoulos, 2014; Sternberg \& Kaufman, 2010). Quite a number of researches examine the link between intrinsic motivation and creativity "individuals are intrinsically motivated when they seek enjoyment, interest, a satisfaction of curiosity, self-expression, or personal challenge in the work" (Amabile, 1997, p. 21). Intrinsic motivation is crucial to achieving creativity. However, in order to enhance creativity, according to Byron and Khazanch (2012), Cerasoli, Nicklin, and Ford, (2014), extrinsic motivators must also be considered - individuals acting due to a reward or recognition may also have a positive impact on creative performance (The importance of expertise is also reflected by the scholars. The term "expert" is used to describe people whose performance is superior to the performance of non-experts in the field and they are identified as a critical element in the creative process (Sternberg, 2006; Kozbelt, Beghetto, \& Runco, 2010). Finally, cognitive abilities or brain-based skills are fundamental for the person to be considered creative. Prior knowledge is a significant part of creativity - the creative person needs to have access to his/ her mental library to create new knowledge. Perception, attention, memory, motor skills, language, visual and special processing, and executive functions play a crucial role in the creative process (Kintsch, 1998).

The performance of the creative person is often influenced by the aspect of the creative environment/ press i.e. the setting or climate in which the creative process takes place. According to Rhodes (1961), the environment should stimulate creation. Soliman (2005) argues that environmental conditions that have a positive effect on creativity refer to the organizational culture, open and honest internal communication, future orientation, autonomy, resources, and best practices. Clear goals, freedom to experiment, a coach that leads by example can stimulate creativity and innovation. Those who define the 
environment as a place, where the creative process takes place (Zhu, 2014; Lewis \& Moultrie, 2005), emphasize physical aspects - creative colors, settings, use of natural materials, the complexity of visual details, etc.

The interaction and cohesion between the Person, Process and Press are vital to produce the creative output (Product).
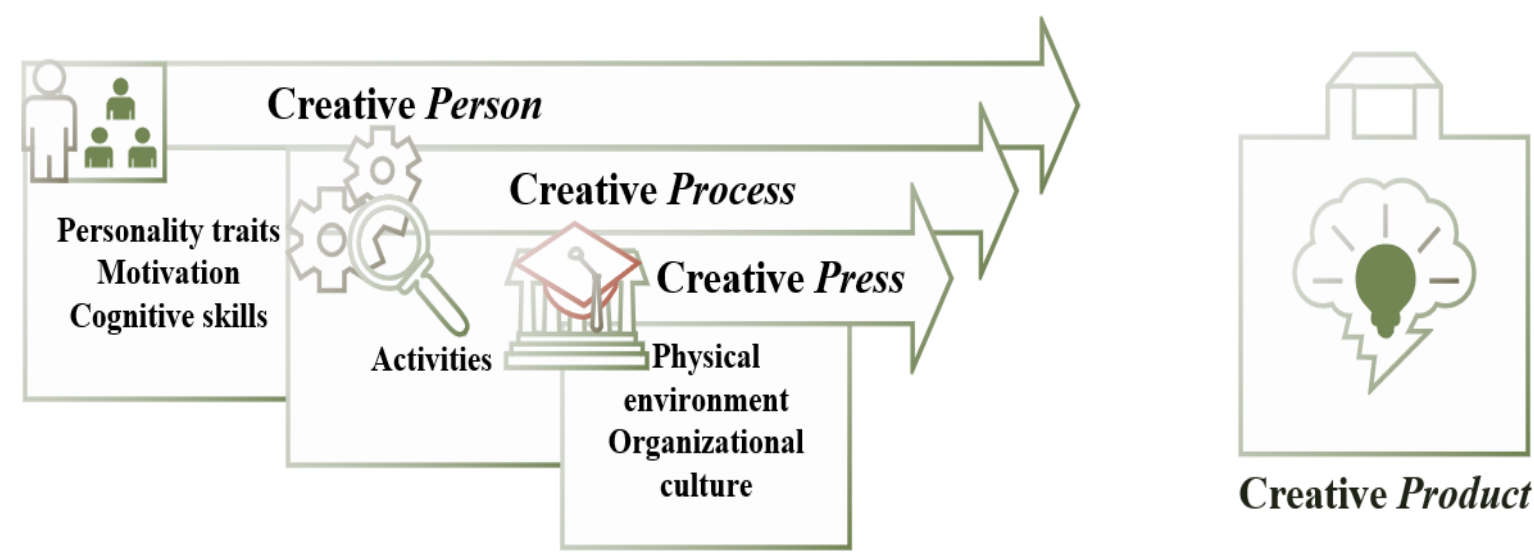

Figure 2 The four $\mathbf{P}$ components of creativity (Adapted from An analysis of creativity ( $p$. 305) by M. Rhodes, 1961, The Phi Delta Kappan)

There are many different ways, methods, tools, and techniques to combine the three clusters in order to get the creative result. To get a group into creative thinking mode, help students to find new perspectives, boost innovation but at the same time promote a safe, non-judgmental atmosphere, the Creative Platform didactic model is used at the Vilniaus kolegija/ University of Applied Sciences, Faculty of Business Management. This study is a part of longitudinal research, started in 2016 by Mačerauskienè and Turčinskaitė-Balčiūnienè (2017). The methodology is meant to develop creativity during regular practical tasks to make it an involuntary reflex and to discover new viewpoints, perspectives and solutions to any business problem (Byrge \& Hansen, 2014). The paradigm of the Creative Platform is based on four pillars: No-Judgement, Task-Focused, Parallel Thinking, and Horizontal Thinking. We are used to judging others - how they act and behave and situations on a personal level. According to the research (Byrge \& Hansen, 2008), both, the positive and the negative judgement is typically more harmful than beneficial, especially when it comes to the creative process. No-Judgement pillar is meant to avoid both the positive judgement and the negative judgement. During the idea generation sessions, students are instructed and trained not to use neither verbal nor expressed by facial or other non-verbal signals judgement and to avoid selfjudgment. None of the participants are asked to perform in front of others and no one monitors the process - there are only the participants and the facilitator in the room. The setting where the creative process takes place is on one hand full 
of visual details but on the other hand, does not contain any personal items (coats, bags, etc.), items that produce smell (coffee, food, etc.) and other unnecessary things. To stay focused on the creative process rather than someone the participant expects to generate the biggest number of ideas or find the most innovative solution as the person has an impressive educational background or work experience, participants are not allowed to introduce to each other. Byrge, Hansen (2008) claim, that the No-Judgement pillar allows participants to be themselves in their performance rather than present how they think they are or how they would like others to think about them.

Students during the creative process might get easily distracted by many factors. Task-Focused pillar requires 100\% concentration on the task. Therefore, the facilitator of the creative process should choose a problem/ challenge or the level of a problem that suits the students participating in the idea generation session best. The participants should be encouraged to use any kind of knowledge they have to solve the problem in a creative way regardless of their social status, cultural background, age, gender, religion or other diversity factors. To fully engage them in the process the facilitator collects the participants' mobile phones, computers, watches, and other potential disturbances. Staying focused on the task the students track of time and find the process of developing new ideas "funny".

Parallel Thinking pillar requires "to focus the thinking of both the individual and all the participants in a group towards one task at a time" (Byrge, Hansen, 2008). Every task or instruction in the creative process is divided into smaller tasks or subtasks. In an ordinary class, a lecturer gives a whole task, e.g. Develop as many ideas as possible for the future bus using "person" stimuli cards. On the Creative Platform, the process is highly structured so the facilitator instructs on how to do and what to do at a given time e.g. 1. Stand up (the second subtask is given after the first is completed); 2. Find a partner who was born in the same month as yourself (the facilitator hands out the "person" training cards and asks not to turn them over); 3. Face your partner; 4. Use a new person analogy every time you have to develop a new idea for a future bus (short demonstration takes place); 5. The one with longer hair starts; 6. Please start now; 7. Please stop now. This is how the pillar of Parallel Thinking creates a concentration of the participants.

Diversified knowledge or Horizontal Thinking pillar ensures using an indirect and creative approach to solve a problem. Being on the Creative Platform students are instructed to look at a situation or problem from different perspectives. In order to solve the introduced challenge, the participants are asked to think as a bus driver, detectives, archeologists, or programmers. "Picture", "Challenge”, "Word", "Up side down" ant other training cards are given to break away from a traditional mode of thinking. 
A course based on the Creative Platform is divided into six phases: Preparation, the Red carpet, Presenting the problem, Idea development, Professional input, and the Blue carpet (see fig. 3).

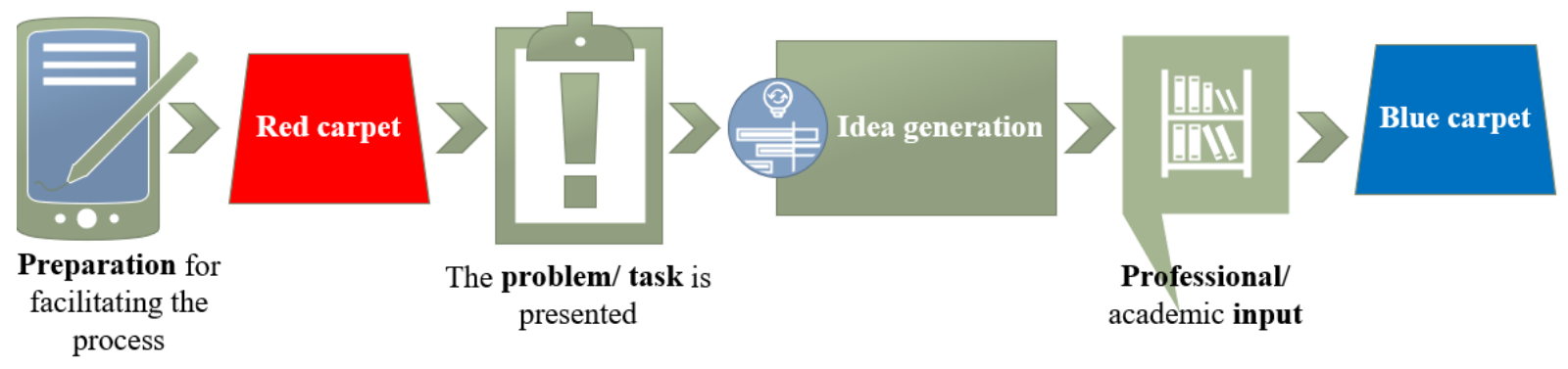

Figure 3 The 6-phase Creative Platform model

Preparation for facilitating the creative process includes gathering a group of participants who possess different knowledge and expertise, organization of physical environment (arrangement of chairs and working space, materials and supplies, etc.) and putting down a minute to minute program of the creative process. The Red carpet ritual is used to get the participants onto The Creative Platform. They are introduced to a different organizational culture guided by the principles of No-Judgment, Task-Focused, Parallel Thinking, and Horizontal Thinking. Performing a number of physical and cognitive tasks students boost their motivation, concentration, and confidence to accept the rules of the facilitator and actively participate in the creative process. The problem/ challenge is presented briefly without any academic input in order not to block the participants' creativity. The problem should be clear and concise - it is important to convey all the needed information but not to elaborate on it. The idea development process might last from 1.5 to 12 hours or even more. The main goal is to develop unique and original ideas by showing fluency i.e. by developing as many as possible. After performing a variety of exercises the shift in vertical thinking to creative thinking appears. The principles of No-Judgment, Task-Focused, Parallel Thinking and Horizontal Thinking actively cultivated in the process lead to the experience of being creative. After the idea generation session, the professional or academic input is brought into the creative process. The participants work on the idea that they want to develop further. The required knowledge is provided by engaging new participants - students from different courses, professors, social partners, etc. to the process. All the participants work under the same rules and principals on the Creative Platform. The last - the Blue carpet phase - is like an exit, process of getting off of the Creative Platform. The students are usually asked to present their ideas to other participants or third parties but are not judged. Only after the completion of the 6 phase model 
students are allowed to socialize in a usual manner. By doing that they are back to the "real world" where the Creative Platform principles, including NoJudgment principle, are forgotten.

The article reviews the outcome - a rich range of creative solutions developed by diverse teams on the Creative Platform applied in different courses.

\section{Methodology}

The participants in this study were 85 students (age range 19 - 28), 38 male and 47 female, studying at higher education institutions in Bordeaux (France), Vienna (Austria), and Ho Chi Minh City (Vietnam). The first group of students (studying in Bordeaux) was the most international group. The Marketing group of 39 students (Bachelor level) represented 14 different nationalities (Lithuania, the Netherlands, Estonia, Romania, Greece, China, Georgia, Belgium, Poland, Germany, the UK, Spain, Portugal, and India). Regarding the participants studying Project management and IT (Bachelor level) at the higher education institutions in Vienna, 12 of them were born in Austria. The other students (16) were born outside Austria and were either full time foreign students (11) or part time students under the Erasmus program (5). Full time students were from Russia (3), Germany (1), India (4), Sri Lanka (1), China (2). Part time students came from Denmark (1), Poland (1), Check Republic (2), Slovenia (1). The Vietnamese group was an interdisciplinary group of 18 students at a Bachelor level as the main criteria of selection to attend the idea generation session was sufficient English language proficiency to participate effectively.

During the idea generation session at a certain point, all the participants were divided into smaller 3 or 4-student groups. Diverse groups of students (gender, cultural, educational background) were formed to promote a variety of different perspectives. None of the participating groups had the experience working together before. Furthermore, 12 lecturers joined the Vietnamese students in phase 5 (academic input) and helped students to add more ideas using their own mental libraries - experiences and knowledge in different business fields. Only two lecturers joined the groups in Bordeaux and three lecturers shared their ideas in Vienna. See table 1 for more detailed information. 
Table 1 Sample

\begin{tabular}{|c|c|c|c|}
\hline $\begin{array}{l}\text { Time and } \\
\text { venue }\end{array}$ & $\begin{array}{l}\text { Countries participants come } \\
\text { from }\end{array}$ & $\begin{array}{l}\text { Educational } \\
\text { background }\end{array}$ & $\begin{array}{l}\text { Groups (No of } \\
\text { group members, } \\
\text { gender) }\end{array}$ \\
\hline $\begin{array}{l}\text { 20-24, } \\
\text { March, } \\
2017, \\
\text { Bordeaux, } \\
\text { France }\end{array}$ & $\begin{array}{l}\text { Lithuania (2), the Netherlands (3), } \\
\text { Estonia (1), Romania (1), Greece } \\
\text { (2), China (5), Georgia (2), } \\
\text { Belgium (3), Poland (1), Germany } \\
\text { (3), the UK (6), Spain (4), } \\
\text { Portugal (4), India (2). } \\
\text { Total no: } 39\end{array}$ & $\begin{array}{l}3^{\text {rd }} \text { year Bachelor } \\
\text { students in } \\
\text { marketing field. }\end{array}$ & $\begin{array}{l}\text { 1.1. }(4-2 \mathrm{M}, 2 \mathrm{~F}) \\
\text { 1.2. }(4-4 \mathrm{M}) \\
\text { 1.3. }(4-3 \mathrm{M}, 1 \mathrm{~F}) \\
\text { 1.4. }(4-2 \mathrm{M}, 2 \mathrm{~F}) \\
\text { 1.5. }(4-1 \mathrm{M}, 3 \mathrm{~F}) \\
\text { 1.6. }(4-4 \mathrm{~F}) \\
\text { 1.7. }(4-1 \mathrm{M}, 3 \mathrm{~F}) \\
\text { 1.8. }(4-4 \mathrm{~F}) \\
\text { 1.9. }(4-2 \mathrm{M}, 2 \mathrm{~F}) \\
\text { 1.10. }(3-3 \mathrm{~F})\end{array}$ \\
\hline $\begin{array}{l}\text { 16-20, } \\
\text { April, 2018, } \\
\text { Vienna, } \\
\text { Austria }\end{array}$ & $\begin{array}{l}\text { Austria (12), Russia (3), Germany } \\
\text { (1), India (4), China (2), Sri Lanka } \\
\text { (1), Denmark (1), Poland (1), } \\
\text { Check Republic (2), Slovenia (1). } \\
\text { Total no: } \mathbf{2 8}\end{array}$ & $\begin{array}{l}2^{\text {nd }} \text { year Bachelor } \\
\text { students in Project } \\
\text { Management and } \\
\text { IT. }\end{array}$ & $\begin{array}{l}\text { 2.1. }(4-2 \mathrm{M}, 2 \mathrm{~F}) \\
\text { 2.2. }(4-2 \mathrm{M}, 2 \mathrm{~F}) \\
\text { 2.3. }(4-3 \mathrm{M}, 1 \mathrm{~F}) \\
\text { 2.4. }(4-3 \mathrm{M}, 1 \mathrm{~F}) \\
\text { 2.5. }(4-1 \mathrm{M}, 3 \mathrm{~F}) \\
\text { 2.6. }(4-1 \mathrm{M}, 3 \mathrm{~F}) \\
\text { 2.7. }(4-4 \mathrm{M})\end{array}$ \\
\hline $\begin{array}{l}\text { 18-22, } \\
\text { March, } \\
\text { 2019, } \\
\text { Ho Chi } \\
\text { Minh, } \\
\text { Vietnam }\end{array}$ & $\begin{array}{l}\text { Vietnam (18) } \\
\text { Total no: } 18\end{array}$ & $\begin{array}{l}1^{\text {st }}-3^{\text {rd }} \text { year } \\
\text { Bachelor students } \\
\text { in Psychology, } \\
\text { Marketing, } \\
\text { Agricultural } \\
\text { Business } \\
\text { Management, and } \\
\text { Entrepreneurship } \\
\text { and Management. }\end{array}$ & $\begin{array}{l}\text { 3.1. }(4-2 \mathrm{M}, 2 \mathrm{~F}) \\
\text { 3.2. }(4-4 \mathrm{~F}) \\
\text { 3.3. }(4-1 \mathrm{M}, 3 \mathrm{~F}) \\
\text { 3.4. }(3-2 \mathrm{M}, 1 \mathrm{~F}) \\
\text { 3.5. }(3-2 \mathrm{M}, 1 \mathrm{~F})\end{array}$ \\
\hline
\end{tabular}

Note. Data about the participant gathered after the idea generation sessions in France, Austria and Vietnam

The three idea generation sessions were organized and facilitated by the author of the article. The Creative Platform methodology that is often applied at the author's home institution in business field studies was brought to Bordeaux in March 2017, Vienna - April 2018, and Ho Chi Minh - March 2019. The facilitator organized 8-hour idea generation sessions under the Creative Platform methodology as an introductory activity to the course. Some theories of individual and organizational creativity, as well as other methods to boost one's creative potential, were provided during the rest of the stay at the hosting institution. The challenge presented to all groups was the same - to develop a future bicycle. Each group was introduced to the principles of No-Judgment, Task-Focused, Parallel Thinking, and Horizontal Thinking, mode of work and performed four exercises (Clap, Exchange presents, The day backwards, Filling 
in the categories) to get on the Creative Platform. To experience idea flow in different categories a number of different stimuli were provided (see fig. 4).

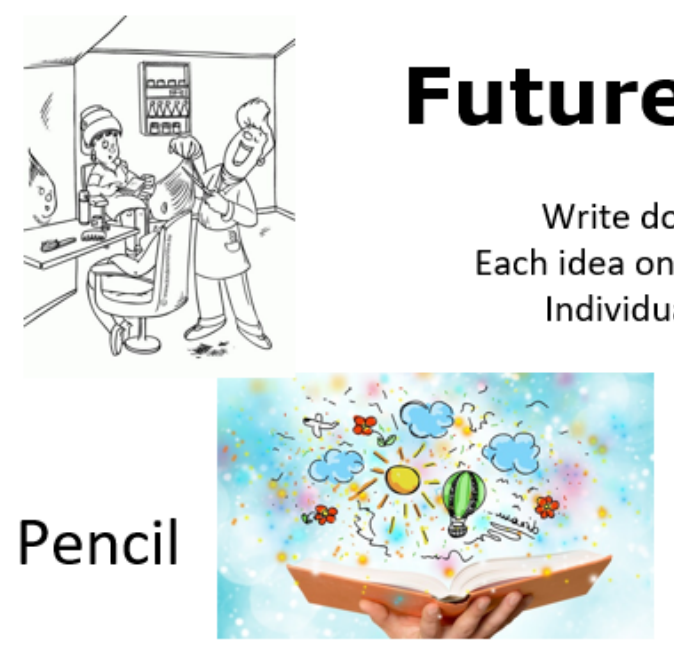

If a pianist was hired to solve this problem what ideas would he come up with?

Vending mashine

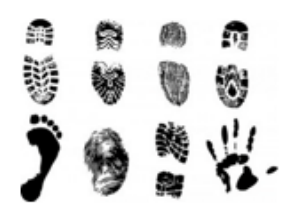

Apply the principle of various cultures in the solution

\section{Aircraft Apply the principle of "volume"}

The solution must be able to be shared

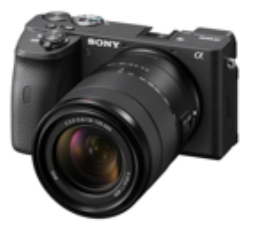

Box

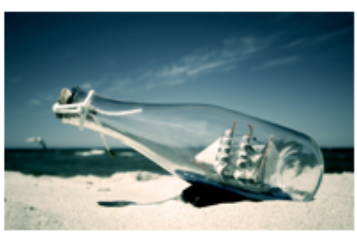

Figure 4 Some of the stimuli used in the idea generation sessions

Note.Compilation of stimuli used in the idea generation sessions (presented in the slides, items pointed at in the room).

The creative process was divided into idea generation individually, idea generation in pairs, selection of idea individually, idea development in pairs, idea presentation in the class, idea development in groups, selection of idea in groups, idea development in groups 2, preparation for presentation, presentation in the class 2, reflection on idea generation session. The set of various tasks to develop students' fluency (ability to generate lots of ideas), flexibility (ability to create different categories of ideas), elaboration (ability to add more details and perspectives to existing idea), and originality (ability to come up with ideas that are unique) was presented in different stages. All the ideas generated and the final 22 ideas were collected and analyzed. Besides the facilitator two more experts (lecturers at the hosting institutions) were invited to evaluate students' ideas according to the following criteria: product originality, elaboration (how 
detailed the idea was), and product's adaptiveness (its ability to solve the existing problem). The aspects of the creative person, creative process, creative press, and creative product were taken into consideration during the reflection.

\section{Research results}

A culture of creative thinking in business studies was quite well developed at the hosted institution in Vienna - creativity methods were practiced during organizational behavior classes. Unfortunately, creativity was not taught as a separate subject at the hosted institutions and was not a part of curricula at Erasmus students' home institutions. On the other hand, some methods/ elements of creativity were introduced in business related subjects such as marketing, project management, entrepreneurship and others at the higher education institution in Bordeaux. Students at the hosted institution in Vietnam were not used to creativity topic and demonstrated a low level of knowledge in creativity methods. Nevertheless, they demonstrated high motivation and good results regarding the ideas.

The future bicycles were presented by 22 diverse groups of students. One idea was selected from the bulk of ideas by each group and developed further in order to launch a future bicycle. The total number of ideas varied from 134 to 201 per group of four students and from 78 to 157 ideas per 3-student group. There was a positive relationship between fluency (the number of ideas) and diversity in the group. The highest level of fluency was reached in the most international as well as interdisciplinary groups as the result of integrating knowledge and ways of thinking from two or more cultures/ disciplines to produce new ideas. These were also mixed groups regarding gender aspect (groups 1.1.; 1.4.; 1.7; 1.9.; 2.2.; 2.4.; 3.1.; 3.3.; 3.4.). The analysis of the data collected disclosed that interdisciplinary groups showed the highest flexibility i.e. the number of different cognitive categories (groups 3.1.; 3.3.; 3.4.; 3.5.). The mean number of categories - 6.25 while the highest number is 11 . Some of the categories indicated: sport related improvements; advertisement/ communication related improvements; technological and technical improvements; additional services related solutions; design related improvements; culture-related solutions; environment friendly solutions; food related solutions, education related solutions, etc. The most original ideas (not detected in other groups) and the ones solving a real problem were generated in groups 1.4.; 2.4.; and 3.3. The ideas were assigned to the categories "education related solution", "culture-related", and "technological and technical improvements". The most detailed ideas (concrete details were added to sketches) were presented in groups 1.3.; 1.7; 1.10.; 2.4.; 2.6.; 3.2.; and 3.3. 
During the reflection, students expressed the following opinions regarding the environment (press aspect) created during the idea generation session the creative process itself: "Phones, watches, and coffee collected was a great toll to wake up creativity. Could be used in other classes"; "It was okay to focus on one idea and to generate other ideas using stimulation"; "It was fun to do short exercises to block our minds from daily problems and help to concentrate them only on creativity"; "I liked that I had to work with people that I've never met in person before"; "We shall continue making mistakes!”; "I enjoyed the strictly structured process although got tired!"; "I really enjoyed how the teacher managed the to keep us active for 8 hours"; "Training was a bit too long in my opinion but it was a huge pleasure not to be judged"; "loved freedom of expressing crazy ideas"; "it was more difficult to work after the professors joined the team"; "had fun but productive time"; "I've never thought I'll work on the same problem with someone studying art!" "it was weird not to give any questions during the trainings".

\section{Conclusions}

Although creativity as a skill is more important today than it has ever been before and it is the skill of the future, still it is often related to art and artists, graphic designers, or painters rather than a business.

The structured paradigm of creativity - the Creative Platform - eliminated the barriers between the disciplines, cultures and other domains and allowed students and lecturers to apply knowledge unlimitedly.

Cohesion between the person, process, and press is extremely important to achieve a creative result. Elimination of judgement in the process and provision of different stimuli enhanced had an evident influence on the participants' fluency and flexibility.

Cultural diversity and interdisciplinary knowledge in the groups generated a better result in terms of quantity and quality and should be continuously used to develop the participants' soft skills and to achieve creative and innovative results.

The environment and process impact on the creative product should be analyzed further and compared to the unstructured idea generation session results.

\section{References}

Amabile, T.M. (1997). Entrepreneurial creativity through motivational synergy. Journal of Creative Behavior, 31, 18-26

Barron, F. (1988). Putting creativity to work. In Sternberg, R.J. (Ed.) The nature of creativity (pp. 76-98). New York, NY: Cambridge University Press. 
Besemer, S.P., \& O'Quin, K. (1999). Confirming the three-factor creative product analysis matrix model in an American sample. Creativity Research Journal, 12(4), 287-296.

Brown, R.T. (1989). Creativity: What are we to measure? In Glover, J.A., Ronning, R.R., and Reynolds, C.R. (Eds.), Handbook of Creativity. New York, Plenum.

Byrge, Ch., \& Hansen, S. (2014). Enhancing creativity for individuals, groups, and organizations - Creativity as the unlimited application of knowledge, 35-46 Frydenlund.

Byrge, Ch., \& Hansen, S. (2008). The Creative Platform: A didactic for sharing and using knowledge in interdisciplinary and intercultural groups JO - SEFI: European Association for Engineering Educatio, 34(3), 235 - 250.

Byron, K., \& Khazanchi, S. (2012). Rewards and creative perfo.rmance: a meta-analytic test of theoretically derived hypotheses. Psychol. Bull., 138, 809-830. DOI: 10.1037/a0027652

Cerasoli, C.P., Nicklin, J.M., \& Ford, M.T. (2014). Intrinsic motivation and extrinsic incentives jointly predict performance: a 40-year meta-analysis. Psychol. Bull., 140, 980-1008. DOI: 10.1037/a0035661

Davis, G. (2004). Creativity is forever (5th edition). Dubuque, Ia: Kendall-Hunt.

Dawson, P.M., \& Andriopoulos, C. (2014). Managing Change, Creativity \& Innovation. (2nd ed.). London: Sage Publications.

Guilford, J.P. (1967). Some theoretical views of creativity. In H. Helson \& W. Bevan (Eds.), Contemporary approaches to psychology (pp. 419-459) Princeton, NJ: Van Nostrand.

Kintsch, W. (1998). Comprehension. A Paradigm for Cognition. Cambridge, MA: Cambridge University Press.

Kozbelt, A., Beghetto, R.A., \& Runco, M.A. (2010). Theories of creativity. In J. C. Kaufman \& R.J. Sternberg (Eds.), The Cambridge handbook of creativity (pp. 20-47). Cambridge: Cambridge University Press. https://doi.org/10.1017/CBO9780511763205.004

Lewis, M., \& Moultrie, J. (2005). The organizational innovation laboratory. Creativity and Innovation Management, 14(1), 73- 83.

MacKinnon, D.W. (1962). The nature and nurture of creative talent. American Psychologist, $17,484-495$.

Mačerauskienė, N., \& Turčinskaitè-Balčiūnienè, A. (2017). Do Differences Make a difference? The Case Based on Creativity Platform. Retrieved from https://www.viko.lt/media/uploads/sites/3/2017/11/9786094360510.pdf

Plucker, A.J., Beghetto, R., \& Dow, G. (2004). Why isn’t creativity more important to educational psychologists? Potentials, pitfalls, and future directions in creativity research. Educational Psychologist, 39(2), 83-96. DOI: https://doi.org/10.1207/s15326985ep3902_1

Rhodes, M. (1961). An analysis of creativity. Phi Delta Kappan.

Soliman, S. (2005). Systems and creative thinking. Cairo, Egypt: Center for Advancement of Postgraduate Studies and Research in Engineering Sciences.

Sternberg, R.J. (2006). The nature of creativity. Creativity Research Journal, 18(1), 87-98. DOI: https://doi.org/10.1207/s15326934crj1801_10

Sternberg, R.J., \& Kaufman, J.C. (2010). Constrains of creativity: Obvious and not so obvious. In J.C. Kaufman and R.J. Sternberg (Eds.), The Cambridge Handbook of Creativity (pp. 467-482). New York, NY: Cambridge University Press.

Tardif, T.Z., \& Sternberg, R.J. (1988). What do we know about creativity? In Sternberg R.J. (Ed.), The Nature of Creativity (chapter 17, pp. 429-440). Cambridge University Press, Cambridge, UK. 
Wallas, G. (1926). The art of thought. London: Jonathan Cape.

Zhu, Y., \& Bargiela-Chiappini, F. (2013). Balancing Emic and Etic: Situated Learning and Ethnography of Communication in Cross-Cultural Management Education. Academy of Management Learning \& Education, 12(3), 380-395. 